with the thoroughness and success with which it has reformed and revivified every branch of higher education. Cloudesley Brereton.

Principal works consulted :-_" Ministère de l'Instruction Publique et des Beaux Arts; (I) Statistique de l'Énseignement Supérieur; (2) Introduction à la Statistique de l'Enseignement Supérieur, par M. L. Liard, Directeur de l'Enseignement Supérieur. (Paris : Imprimeric Nationale, MDCCCC.) (3) "Législation et Jurisprudence de l'Instruction Publique. Extrait du Répertoire du Droit administratif." Première partic, Historique et Organisation générale; Deuxième partie, Enseignement Supérieur; Sixième partie, Écoles ne relevant du Ministère de l'Instruction Publique. (Paris : P. Dupont, 1903.)

\section{THE RESUSCITATION OF THE APPARENTLY} DROWNED.

I $\mathrm{N} 1862$ a committee, which included several eminent medical men and physiologists-amongst the latter Dr., now Sir, John Burdon Sanderson- -was appointed by the Royal Medical and Chirurgical Society to investigate the phenomena attendant upon drowning, and the methods which had been recommended for the recovery of apparently drowned persons. That committee made a number of experiments in man upon the dead subject, and upon animals during life, and the results they obtained were duly published in the Transactions of the society. But it appeared important to renew the inquiry with modern methods, and a second committee for the investigation of this important subject was accordingly appointed a few years ago, with Prof. Schäfer as chairman. This second committee attempted, in the first instance, to pursue the inquiry as to the best means of carrying on artificial respiration, in the same manner as the 1862 committee, i.e. upon the cadaver, but met with grave difficulties from the outset in the enormous resistance which the condition of rigor mortis sets up to effecting changes of volume of the chest, a difficulty which had been also met by the earlier committee, and very imperfectly surmounted. The new committee accordingly decided to discard the cadaver, and to endeavour to determine in the living human subject how great an amount of air could be moved into and out of the lungs by movements imparted to the thorax by the agency of external force. This force was applied either by intermittent traction upon the arms, or by intermittent pressure upon the thorax, the subject being either in the supine or prone position, and remaining perfectly passive during the short period of the experiment. The amount of air taken in and given out was measured in a graduated vessel, or by means of an ordinary gasnmeter.

The results showed that by all methods which have been suggested for the performance of artificial respiration, viz. the Silvester traction method, the Marshall Hall rolling method plus compression of thorax, the Howard method of compression of thorax in the supine position, and also a similar method of pressure upon the thorax with the subject in the prone or semiprone position, an amount of air can be drawn into and driven out of the thorax which is at least as great as the amount of air exchanged in the ordinary tidal respirations of the individual. This being so, it is evident that, in selecting a method of artficial respiration for restoring the drowned, one should be guided less by the actual amount of air which any given method is capable of exchanging than by other considerations, such as the facility offered for the escape of water and mucus from the air passagres, and the preventing of the tongue from falling back and blocking the fauces, both of which objects are better attained by the lateral and prone than by the supine position. It was further clear that it is more easy to effect artificial respiration by exerting intermittent pressure upon the thorax than by arm traction, and although the committee do not give instructions for the restoration of the apparently drowned in their report, it is obvious that their conclusions point to the adoption of the prone or semi-prone position of the subject, and to rhythmically intermitted pressure upon the thorax, as the methods which are likely, in the circumstances of drowning, to yield the best results.

The experiments upon animals (which were performed almost entirely upon anæsthetised dogs) are, it is believed, the first in which all the phenomena connected with the circulation and respiration have been graphically recorded during the process of drowning and subsequent resuscitation by artificial respiration. The chief points which they illustrate are the very large amount of water which can be taken into the lungs and become entirely absorbed into the system within a few minutes, without producing any but quite temporary symptoms, the great amount of vagal stimulation which is produced during drowning, and which is, in some instances, sufficient to arrest the heart's action almost entirely, and the extreme variability in the power of resistance to drowning in different individuals of the same species, so that, while a submersion of two minutes is fatal to some individuals, one of seven or eight minutes, or even more, can be borne by others with a fair chance of recovery as the result of the application of artificial respiration. The experiments all point to the supreme importance of commencing artificial respiration at the earliest possible moment, and are, therefore, condemnatory of all instructions for the recovery of the apparently drowned which direct that, before proceeding to apply artificial respiration, the patient should be divested of clothing, hartshorn should be applied to the nostrils, and various other remedies attempted-. all of which merely serve to waste time, every second of which is invaluable for combatting the actual condition which is threatening life, viz. the lack of oxygenation of the blood. Incidentally it was found in the course of these experiments that, without sufficient aëration of the blood, even the most powerful cardiac and vascular stimulant-such, for example, as the extract of suprarenal capsule-is entirely unable to assist recovery.

The experiments upon the cadaver were chiefly performed by Mr. Pickering Pick, Mr. Henry Power, and Dr. J. S. Bolton, in London; those upon the living subject by Prof. Schäfer and Dr. P. T. Herring in the physiological laboratory of the University of Edinburgh. The report of the committee was read by Prof. Schäfer at a largely attended meeting, held on May 26 last, at the rooms of the society in Hanover Square.

\section{NOTES.}

$W_{F}$ regret to learn that on Saturday, July $25, \mathrm{M}$, Prosper Henry, of the Paris Observatory, was found lying dead in the La Valoise Valley near Pomogen at an altitude of 1600 metres, in the French Alps. His death appears to have been due to congestion caused by extreme cold. M. Henry was buried at $\mathrm{Nancy}$, his birthplace, on August I. $\Lambda$ number of astronomers was present at the sad ceremony, among them being M. Callandreau, of the Paris Academy of Sciences; MM. Borchart and Fraissinet, of the Paris Observatory; and M. Trépied, director of the Algiers Observatory. M. Prosper Henry and his brother, M. Paul Henry, were attached to the Paris Observatory in 1865 , and their work is well known in the astronomical world. Between $187^{2}$ and 1882 they discovered fourteen asteroids,

$$
\text { NO. } 1762 \text {, VOL. 68] }
$$

